\title{
Alkalosis, CTCAE
}

National Cancer Institute

\section{Source}

National Cancer Institute. Alkalosis, CT CAE. NCI Thesaurus. Code C143270.

A disorder characterized by abnormally high alkalinity (low hydrogen-ion concentration) of the blood and other body tissues. 